\title{
PERTENCIMENTO À CLASSE SOCIAL E PRÁTICAS CORPORAIS: REVISANDO O TEMA NA LITERATURA E ENSAIANDO RELAÇÕES POSSÍVEIS ${ }^{1}$
}

\author{
Breno Brey D'auria \\ Especialista em Futebol e Futsal/Estácio \\ Universidade Federal de Mato Grosso do Sul/UFMS \\ b_brey@hotmail.com \\ Cristiano Mezzaroba \\ Doutor em Educação/UFSC \\ Universidade Federal de Sergipe/UFS \\ cristiano_mezzaroba@yahoo.com.br \\ Silvan Menezes dos Santos \\ Doutor em Educação Física/UFPR \\ Universidade Federal de Mato Grosso do Sul/UFMS \\ silvan.menezes@ufms.br
}

\section{Resumo}

Objetivo: Refletir de forma ensaística, no sentido de compreender como uma literatura específica do campo da Sociologia tem interpretado o conceito de classe social e as relações que estipulamos quanto às possibilidades de acesso às práticas corporais de crianças e adolescentes.

Metodologia: Inicialmente realizamos uma Revisão Sistemática, com base no protocolo (PRISMA) e na sequência desenvolvemos um ensaio, discutindo o conceito de classe social e a relação que tal categoria sociológica estabelece com as práticas corporais de crianças e adolescentes.

Originalidade/relevância: A relevância do estudo está em refletir sobre os conceitos de classe social e do "efeito de distinção", para compreender como eles influenciam o acesso e o "gosto" por determinadas práticas corporais, contribuindo assim para um melhor entendimento dos mecanismos sociais intervenientes nesse fenômeno.

Principais resultados: Os estudos evidenciam que fatores como a classe social, a constituição familiar, a estrutura e o nível de segurança dos bairros influenciam o acesso e o tipo de prática corporal que as pessoas acabam se envolvendo. Com relação ao conceito de classe social utilizado pelos estudos, ficou evidente que a maioria possui uma visão economicista sobre essa questão, entendendo classe social como apenas "faixa de renda".

Contribuições teóricas/metodológicas: Procuramos evidenciar a necessidade dos pesquisadores do campo das políticas públicas e dos agentes políticos pensarem não apenas em indicadores demográficos como o IDH, mas também nas questões simbólicas para melhor entender e propor ações voltadas para as práticas corporais de crianças e adolescentes.

Palavras-chave: Distinção social. Atividade física e saúde. Juventude. Infância.

\section{Cite como}

American Psychological Association (APA)

D’Auria, B. B., Mezzaroba. C., \& Santos, S. M. dos. (2021, maio/ago.). Pertencimento à classe social e práticas corporais: revisando o tema na literatura e ensaiando relações possíveis. PODIUM Sport, Leisure and Tourism Review, São Paulo, 10(2), 54-80. https://doi.org/10.5585/podium.v10i2.18584.

\footnotetext{
${ }^{1}$ Agradecemos a contribuição do Laboratório de Psicologia do Esporte e do Exercício (LAPE/CEFID/UDESC), em específico aos professores Alexandro Andrade e Guilherme Torres Vilarino pela orientação do estudo original, defendido como Trabalho de Conclusão de Curso no referido centro e universidade.
} 


\title{
BELONGING TO SOCIAL CLASS AND CORPORAL PRACTICES: REVIEWING THE TOPIC IN THE LITERATURE AND REHEARSING POSSIBLE RELATIONSHIPS
}

\begin{abstract}
Objective: Reflect on a systematic order seeking to understanding how specific the lectures in sociological field area has interpreted the social class concept and stipulated relations between physical practices, children and teenagers.

Methodology: Originally realize a systematic review based on PRISMA's protocol, then we followed by an essay discussing the correlation between social class and the physical practices of kids and teens. Originality/relevance: The relevance of the study is to reflect on the concepts of social class and the "segregation effect", to understand how it influences access and tastes for certain body practices, thus contributing to a better understanding of the mechanisms social actors involved in this phenomenon.

Main results: Studies shows that factors such as social class, family constitution, structure and the neighborhood's security level influences the access and the type of body practice that people end up practicing. Regardless the concept of social class used by the studies, it was evident that most shows an economic view for this issue, understanding social class as just "low income class".

Theoretical / methodological contributions: We seek to highlight the aim for researchers in the public policies field, also political agents to think not only of demographic indicators such as the HDI, but also for symbolic issues to better understand and propose actions needed at the corporal practices of children and adolescents.
\end{abstract}

Keywords: Social distinction. Physical activity and health. Youth. Childhood.

\section{PERTENENCIA A CLASES SOCIALES Y PRÁCTICAS CORPORALES: REVISIÓN DEL TEMA EN LA LITERATURA Y ENSAYO DE POSIBLES RELACIONES}

\section{Resumén}

Objetivo: Reflexionar de manera ensayística, para comprender cómo una literatura específica en el campo de la Sociología ha interpretado el concepto de clase social y las relaciones que estipulamos respecto a las posibilidades de acceso a las prácticas corporales de niños y adolescentes.

Metodología: Inicialmente realizamos una Revisión Sistemática, con base en el protocolo (PRISMA) y luego desarrollamos un ensayo, discutiendo el concepto de clase social y la relación que establece con las prácticas corporales de niños y adolescentes.

Originalidad/relevancia: La relevancia del estudio es reflexionar sobre los conceptos de clase social y el "efecto distinción", para comprender cómo influyen en el acceso y "gusto" por determinadas prácticas corporales, contribuyendo así a una mejor comprensión de los mecanismos sociales involucrados en este fenómeno.

Principales resultados: los estudios muestran que factores como la clase social, la constitución familiar, la estructura y el nivel de seguridad del barrio influyen en el acceso y el tipo de práctica corporal en la que terminan involucrándose las personas. En cuanto al concepto de clase social utilizado por los estudios, se evidenció que la mayoría tiene una visión económica sobre este tema, entendiendo la clase social solo como "nivel de ingresos".

Contribuciones teóricas/metodológicas: Buscamos resaltar la necesidad de que los investigadores en el campo de las políticas públicas y los agentes políticos piensen no solo en indicadores demográficos como el IDH, sino también en temas simbólicos para comprender mejor y proponer acciones dirigidas a las prácticas corporales de niños y adolescentes.

Palabras llave: Distinción social. Actividad física y salud. Juventud. Infancia. 
D’Auria, B. B., Mezzaroba. C., \& Santos, S. M. dos. (2021, maio/ago.). Pertencimento à classe social e práticas corporais: revisando o tema na literatura e ensaiando relações possíveis

\section{Introdução}

A prática de esportes e de atividade física é algo extremamente difundido e estimulado atualmente. Especialmente para crianças e adolescentes é destacado o importante papel que ela desempenha na socialização, educação, saúde e qualidade de vida (Glaner, 2003; Alves Junior, 2008; Silva \& Costa Junior, 2011; Donnelly et al., 2016). Neste ensaio trataremos tais práticas como práticas corporais, ou seja, uma compreensão/conceito polissêmico que diz respeito a toda uma cultura corporal de movimento, conforme Fraga, Carvalho e Gomes (2012); a qual busca superar a fragmentação na constituição do ser humano, denotando uma crítica à organização de vida contemporânea, além dessa ampliação conceitual ser influenciada pelas ciências humanas e sociais (Lazzarotti Filho et al., 2010). Ainda nesta perspectiva, Silva e Damiani (2005, p. 23-24) definem que o “[...] termo prática deve ser compreendido em sua acepção de 'levar a efeito' ou 'exprimir' uma dada intenção ou sentido e fazê-lo, neste caso, por meio do corpo". Neste sentido, práticas corporais são, nas suas diferentes formas, construções culturais e um tipo de linguagem - a do corpo. Podemos exemplificar tais práticas, portanto, como as múltiplas formas de jogar, de dançar, de se movimentar, de se expressar etc.

Uma das principais características que podemos observar em diferentes sociedades, especialmente naquelas centrais ao desenvolvimento global, é o elevado aumento de comportamento dito "sedentário" e a redução no nível de atividade física em crianças e adolescentes (Colley et al., 2013). Dentre as hipóteses sugeridas sobre esse fato, está a atribuição de uma certa "culpa" devido à utilização de videogames, smartphones e computadores como a principal atividade de lazer das crianças e adolescentes (Carson et al., 2016), ou seja, tem-se atribuído ao uso constante e intenso das tecnologias o motivo das novas gerações cada vez se movimentarem menos corporalmente.

Contudo, o nível de prática de atividade física é uma variável multifatorial, sendo que apenas a acessibilidade a novos recursos tecnológicos não é capaz de explicar sozinha o comportamento ativo ou sedentário. Outros fatores como características físicas, comportamentais, ambientais, escolares e socioeconômicos são fundamentais para a compreensão do assunto (Viana, 2014). Subjaz tal entendimento a concepção dos determinantes sociais de saúde (Zioni \& Westphal, 2007), quanto à própria interpretação mais ampliada do que vem a ser saúde, ou seja, elementos que determinam socialmente o que podemos entender por saúde, como a dimensão material (como habitação, alimentação, trabalho, saneamento e outros), além dos aspectos psicossociais, comportamentais e biológicos. 
D’Auria, B. B., Mezzaroba. C., \& Santos, S. M. dos. (2021, maio/ago.). Pertencimento à classe social e práticas corporais: revisando o tema na literatura e ensaiando relações possíveis

Um importante fator que deve ser considerado nas pesquisas que envolvem o nível de práticas corporais e os "comportamentos" dos sujeitos se refere ao conceito de classe social. Inclusive, esta é uma definição que tem sido mencionada nos estudos sobre o tema, mas talvez sem o destaque necessário, ou quando destacada, aparece sem a profundidade exigida.

Muitas vezes confundida com "faixas de renda" (Souza, 2013a), devemos diferenciar o termo "classe social" no senso comum com a categoria/conceito "classe social", o qual, segundo Souza (2013a, p. 53), volta a ser considerado como "mecanismo explicativo do funcionamento da sociedade como um todo". Ainda segundo Souza (2013a), se conseguimos entender o conceito de classe social como mecanismo totalizador de uma sociedade específica, poderemos, então, compreender as estruturas de dominação social em todas suas dimensões. Na sequência de nosso ensaio traremos uma discussão mais específica e densa quanto ao conceito de classe social a partir dos escritos do sociólogo brasileiro Jessé Souza (2005a; 2005b; 2013a; 2013b), que nos auxiliam a relacionar práticas corporais e classes sociais.

Observa-se que crianças de classes sociais mais altas e com pais com maior nível educacional são mais ativas fisicamente e passam menos tempo assistindo TV se comparado com crianças de classes sociais mais baixas (Kantomaa et al., 2007; Fairclough et al., 2009; Gorely et al., 2009; Jekauc et al., 2013; Lampinen et al., 2017; Wjjtzes et al., 2014). Segundo a literatura, isso se deve ao fato de que crianças de classe social mais alta possuem mais oportunidades e são mais incentivadas pelos pais, que possuem maior preocupação com a saúde, enquanto que para crianças de baixo status social, a TV muitas vezes se apresenta como a principal atividade no tempo de lazer (Gorely et al., 2009; Fairclough et al., 2009).

Visualizamos aqui, baseados em uma breve revisão, questões que são trabalhadas por Souza $(2005 b ; 2013 a ; 2013 b)$ em relação às compreensões quanto à classe social. O sociólogo brasileiro, baseado nos escritos de Pierre Bourdieu e Charles Taylor, demonstra os contornos existentes entre o capital econômico (acesso a recursos financeiros) e o capital cultural (acesso a bens e serviços culturais), os quais, ao mesclarem-se, são convertidos também em capital social (no sentido das relações que são estabelecidas pelos sujeitos que vão incorporando possíveis habitus ao frequentar clubes, academias, escolas etc.). Isso evidencia também, por sua vez, um capital corporal a partir de distinções de classe ${ }^{2}$ - significa dizer, resumidamente, para

\footnotetext{
${ }^{2}$ Nas palavras de Rojas, Grinszpun e Seid (2010, p. 10): “[...] Los privilegiados tienden a evitar las vulgares aglomeraciones y a buscar en otros momentos o lugares la exclusividad y estetización de las prácticas, que se caracterizan por los espacios reservados, los compañeros elegidos, grandes inversiones de tiempo y esfuerzo de aprendizaje - a menudo precoz y debido a la tradición familiar -, competiciones altamente ritualizadas y regidas por el fair-play, intercambios deportivos altamente 'civilizados' con exclusión de toda violencia física o verbal y de contacto directo entre los adversarios. Las clases populares tienden a tener una relación instrumental con el cuerpo y por ello a elegir deportes que exigen grandes esfuerzos, sufrimientos o riesgos al poner en juego el cuerpo mismo. Los deportes populares están tácitamente asociados
} 
D’Auria, B. B., Mezzaroba. C., \& Santos, S. M. dos. (2021, maio/ago.). Pertencimento à classe social e práticas corporais: revisando o tema na literatura e ensaiando relações possíveis

este momento, que pertencer a uma determinada classe social é o fator que permite, por um lado, conhecer e praticar golfe ou tênis, ou mesmo, limitar-se a jogar futebol por toda a vida.

As dificuldades de acesso a ambientes adequados para a prática esportiva e o baixo nível socioeconômico são apontados em estudos recentes como fatores impeditivos de boa parte da população alcançar níveis adequados de atividade física (Stevens et al., 2017). Gonçalves e Franco (2016) destacam que no Brasil, o baixo estrato social é um fator limitador de prática de atividade física por crianças e adolescentes.

Dados obtidos pela fundação $\mathrm{ABRINQ}^{3}$ através do relatório "Cenário da Infância e Adolescência no Brasil” apontam que 40\% das crianças até 14 anos vivem na pobreza. Segundo os últimos dados da Pesquisa Nacional por Amostra de Domicílio (PNAD) feita pelo IBGE (Instituto Brasileiro de Geografia e Estatísticas) no ano de 2015, cerca de 100 milhões de brasileiros a partir dos 15 anos de idade não praticam nenhum tipo de atividade física. Isso representa cerca de $62,1 \%$ da população nesta faixa etária.

O baixo índice de atividade física entre os jovens é preocupante, pois o sedentarismo apresenta graves consequências para a saúde, como o aumento de peso, que acarreta em uma maior probabilidade de desenvolver doenças cardiovasculares, metabólicas e até o desenvolvimento do câncer (Fogelholm, 2010; Gualano \& Tinucci, 2011; Jung et al., 2013). Além disso, muitos comportamentos adquiridos na infância e adolescência permanecem na fase adulta, sendo que os reflexos dessa dinâmica são claramente sentidos em escala global. Em 2010, por consequência da inatividade física, 3,2 milhões de pessoas morreram de forma prematura no mundo (Lee et al., 2012).

Com o cuidado para não cairmos no "discurso fácil" de culpabilizar os sujeitos - a “culpabilização das vítimas", que costuma atribuir julgamentos como preguiçosos aos indivíduos sedentários e obesos ou mesmo que as pessoas "não fazem porque não querem", entre tantos outros - apontamos a ressalva que os comportamentos adquiridos nessa dinâmica social devem ser analisados considerando, justamente, o processo como resultante das desigualdades. Propomos, portanto, um olhar para o fenômeno em questão a partir da estratificação social por classes privilegiadas ou vulneráveis, com acesso (facilitado) a bens e

con la juventud y el despilfarro de energía física y sexual, mientras que los deportes 'burgueses' extienden mucho más allá de la juventud la edad límite de su práctica y son practicados por el mantenimiento físico y beneficio social que proporcionan. Además de la edad biológica, las diferencias en edad social contraponen a edad biológica idéntica a las fracciones dominadas y a las fracciones dominantes o a las nuevas y las establecidas, manifestándose en la oposición entre deportes tradicionales y formas nuevas de deportes clásicos o los deportes nuevos, como los deportes californianos."

${ }^{3}$ Associação Brasileira dos Fabricantes de Brinquedo. 
D’Auria, B. B., Mezzaroba. C., \& Santos, S. M. dos. (2021, maio/ago.). Pertencimento à classe social e práticas corporais: revisando o tema na literatura e ensaiando relações possíveis

direitos, ou sem acesso às condições mínimas e dignas de viver a partir do que a modernidade apresenta.

Desta forma, estudos que identifiquem a relação de pertencimento à classe social com o nível de atividade física (práticas corporais) das pessoas são necessários para compreendermos de forma mais ampliada e aprofundada mecanismos que podem revelar motivos (comportamentos individuais, gostos etc.), mas também desvelar determinações estruturais (limitações financeiras, impossibilidade de acesso às estruturas de esporte, lazer e práticas corporais diversas etc.) que evidenciem que o pertencimento a uma classe social interfere de maneira decisiva nas possibilidades de práticas corporais do conjunto da população de um país. Assim, o objetivo do estudo, em que operamos uma revisão sistemática, é exercitar a reflexão, de forma ensaística, no sentido de compreender como uma literatura específica do campo da Sociologia tem interpretado o conceito de classe social e as relações que estipulamos quanto às possibilidades de acesso às práticas corporais de crianças e adolescentes.

\section{Marco teórico-conceitual quanto à categoria "classe social"}

Compreender e definir o conceito de classe social tem requerido aprofundamento e abrangência no contexto das sociedades complexas e, sobretudo, com o avanço da modernidade. Para além dos parâmetros materiais e econômicos normalmente utilizados para estabelecer os modos de organização e de estratificação, tem-se buscado outras referências e dimensões que ajudam a melhor explicar o porquê e o que determina os diferentes modos possíveis de se viver e de se existir, seja nos centros ou nas periferias globais.

Coutinho e Barros (2013) comentam sobre as mais diversas formas para se categorizar e definir classe social. Informam que pode ser por renda mensal a partir de determinada ocupação profissional; por despesa com bens essenciais e com bens supérfluos, dado o nível de renda (dimensão do consumo determinando pertencimento a classe social); por gasto calórico ${ }^{4}$; por grau de vulnerabilidade 5 ; ou, a partir do proposto pela ABEP - Associação Brasileira de

\footnotetext{
4 “O caso do consumo calórico, por duas razões, revelou-se um dos menos propícios à definição para classe média: a) a partir de um certo nível, as pessoas não passam a consumir mais calorias somente porque ficam mais ricas, o que dificulta a identificação do limite superior da classe média (levando à necessidade de adoção de um critério misto, um para o limite inferior e outro para o superior); e, b) o consumo calórico diário tradicionalmente recomendado, de $2.100 \mathrm{kcal}$, não é consumido qualquer que seja o ponto da distribuição de renda, o que faria com que toda a população fizesse parte da classe baixa (assim, teria que arbitrar um novo nível de consumo calórico mínimo para se obter o limite inferior da classe média)." (Coutinho \& Barros, 2013, p.136).

5 "Segundo essa perspectiva, as classes baixa, média e alta são determinadas por diferenças na probabilidade de virem a ser pobres (ou permanecerem pobres) no futuro imediato. Assim, a classe alta seria aquela formada por pessoas com baixo grau de vulnerabilidade, isto é, com baixíssima probabilidade de se tornarem pobres no futuro imediato. De forma similar, a classe baixa seria aquela formada por pessoas com alto grau de vulnerabilidade, ou seja, com elevada probabilidade de se tornarem pobres no futuro imediato. A classe média seria, então, formada por aquelas com nível intermediário de vulnerabilidade, suficientemente elevado, no entanto para que passem a ter genuíno interesse pelo longo prazo restaria agora arbitrar quais os níveis de vulnerabilidade à pobreza associados ao início e ao fim da classe média." (Coutinho \& Barros, 2013, p.137).
} 
D’Auria, B. B., Mezzaroba. C., \& Santos, S. M. dos. (2021, maio/ago.). Pertencimento à classe social e práticas corporais: revisando o tema na literatura e ensaiando relações possíveis

Empresas de Pesquisa, também utilizado pelo IBGE, que divide a população nas classes A, B, C, D e E.

Souza (2013a, p. 130) considera que “[...] compreender a produção e a reprodução das classes sociais é a 'chave mestra' para o desvelamento do 'mistério' do funcionamento da sociedade como um todo." Mas o que são as classes sociais?

O entendimento quanto às classes sociais foi possível graças às contribuições de Karl Marx, um dos fundadores da Sociologia, o qual atribuía que, nas sociedades capitalistas, o fator econômico relacionado a cada sujeito - a partir da divisão social do trabalho - o colocava em um determinado setor da sociedade: lembremos que conforme as ideias marxistas, há duas formas de "ser" e "estar" no mundo social, ou como detentores dos meios de produção (a burguesia dominante, a elite) ou como os trabalhadores (o proletariado, que vende sua força de trabalho).

Segundo Souza (2013a), a compreensão de Marx - embora deva ser considerado seu caráter pioneiro - recai numa visão "economicista" do conceito de classe social, ou seja, "[...] a crença explícita ou implícita, de que a variável econômica por si só esclarece toda a realidade social" (Souza, 2013a, p. 136).

Neste trabalho, conforme já anunciado, acompanhamos a proposta de interpretação sobre classe social e sobre desigualdades de Jessé Souza (2003; 2004; 2005a; 2005b; 2006; 2013a; 2013b; 2014). O referido sociólogo mobiliza referenciais clássicos da Sociologia Contemporânea para propor uma explicação sobre as duas questões, que leva em consideração componentes políticos e socioculturais implícitos a elas. Em síntese, o propósito dele é superar as teorias tradicionais personalistas, patrimonialistas, economicistas e, mais recentemente, as racialistas, que procuram homogeneizar ou reduzir a discussão acerca do tema no Brasil a parâmetros como as relações pessoais, a faixa de renda e/ou a cor da pele como determinantes da estratificação social (Souza, 2014).

Para isso, Jessé Souza dialoga com Pierre Bourdieu, por considerar que há criatividade na forma como o referido sociólogo operou possibilidades teórico-metodológicas quanto às classes sociais, "[...] com um potencial criativo muito mais penetrante, esclarecedor e sofisticado do que seu uso por Marx" (Souza, 2013a, p. 141). Souza (2013a) defende a necessidade de pensar o termo "capital" não apenas àquilo que ele revela à primeira vista, que seria uma categoria econômica (embora seja decisivo em algumas disputas), mas vinculá-lo à apropriação de um elemento simbólico que evidencia incorporação de uma aprendizagem ao 
D’Auria, B. B., Mezzaroba. C., \& Santos, S. M. dos. (2021, maio/ago.). Pertencimento à classe social e práticas corporais: revisando o tema na literatura e ensaiando relações possíveis

longo da vida e no contato com instituições culturais: observar que classes sociais exige uma compreensão tanto do capital econômico como do capital cultural.

O autor também dialoga com o filósofo social canadense Charles Taylor, para o qual o entendimento de categorias como de classe social sinaliza a relevância de compreendê-las enquanto "instituições", em que "[...] julgamos socialmente uns aos outros baseados nas figuras do "produtor útil' e da 'personalidade sensível"” (Souza, 2013a, p. 153).

De acordo com Souza (2014), as interpretações homogeneizantes e/ou reducionistas sobre a questão de classe social contribuem fortemente para a perpetuação das profundas desigualdades existentes nas sociedades modernas globais. Para o autor, é justamente porque essas ideias se associam a interesses de classes dominantes e pouco esclarecem sobre o problema, que elas ganham circulação e tornam-se hegemônicas nos espaços de educação formal e não formal. Ou seja, nesta perspectiva, depreende-se que em alguma medida a atividade intelectual em torno do tema tem contribuído, ainda que na maioria das vezes inconscientemente, para a perpetuação dos mecanismos de dominação de classe por não enfrentar a complexidade, a profundidade e as raízes da problemática. É com esta preocupação que adotamos a perspectiva do autor para interpretar o conceito de classe social da literatura científica sobre as práticas corporais (comumente relacionadas à saúde).

Também podemos questionar, a partir desses entendimentos, se é possível pensar em um "aprendizado de classe" em relação às práticas esportivas e corporais. Ou seja: nossa inserção "automática" e "naturalizada" à classe social que pertencemos ao nascermos e que ao longo da vida vamos sendo socializados - pela família, grupos de amigos, escolas, universidade, ocupação profissional etc. - determina, de certa forma, no sentido de nos "conformar" ou nos “apropriar" ou mesmo de nos "limitar" a certas práticas corporais?

Luc Boltanski (2004) desenvolveu estudos pioneiros quanto à relação entre pertencimento às classes sociais e instrumentalização do corpo. Para o autor francês, que pressupõe as compreensões conceituais operadas por Bourdieu (em especial, de habitus e hexis corporal), são hábitos de classe que explicitam aspectos de uma cultura corporal que é específica para grupos sociais heterogêneos ${ }^{6}$, como por exemplo, em relação às condutas sexuais, aos comportamentos sanitários, no vestuário, na alimentação, na forma de compreender a relação saúde-doença, nos cuidados corporais etc. Boltanski (2004) denomina tal processo como "código de boas maneiras corporal":

\footnotetext{
${ }^{6}$ Lembremos que na configuração da sociologia empírica francesa, as diferentes classes são agrupadas a partir dos agricultores, passando pelos operários, depois os assalariados terciários e técnicos assalariados, e assim por diante.
} 
D’Auria, B. B., Mezzaroba. C., \& Santos, S. M. dos. (2021, maio/ago.). Pertencimento à classe social e práticas corporais: revisando o tema na literatura e ensaiando relações possíveis

Porque tal código, profundamente inconsciente, só se exprime, como os códigos linguísticos, através de seus produtos, ou seja, na prática daqueles cuja prática ele rege, só pode ser percebido pela observação, análise e comparação das práticas corporais dos membros dos diferentes grupos sociais [...]. (Boltanski, 2004, p. 136).

Lopes (2014), no texto "Esporte e classe social na sociologia de Pierre Bourdieu”, tece considerações a respeito dessas relações, principalmente quanto ao gosto esportivo não ser algo genético ou naturalizado, e sim, uma construção social e cultural (uma incorporação ao longo de nossas vidas, sendo estruturado pelo habitus de classe), a partir, também, da distinção social, como propõe Bourdieu. Segundo Lopes (2014):

[...] o valor atribuído pelas classes populares para as práticas esportivas possuiria um peso muito inferior do daquele atribuído pelas classes dominantes. Em última instância, estas é que imporiam a definição e a função legítima do esporte. Notemos, todavia, que, segundo o autor, as barreiras de entrada para o consumo das modalidades esportivas legítimas não são somente de ordem econômica. A prática de alguns esportes exigiria o aprendizado cedo e técnicas de sociabilidade. (Lopes, 2014, p. 179)

Para Souza $(2003 ; 2004)$ as classes sociais são estratos classificatórios definidos pelo tipo de personalidade e de disposições de comportamento de diferentes grupos e comunidades humanas, que atendem ou não às demandas objetivas de produtividade e utilidade do modelo socioeconômico vigente.

É a partir desse critério psicossocial, como pré-condição fundante da estratificação das classes, que os determinados segmentos da sociedade vão ou não gozar de dignidade, de respeito e de reconhecimento social. Sob esta ótica, portanto, o autor propõe que é a ideologia do desempenho como hierarquia moral, produzida e legitimada nas sociedades modernas (Souza, 2006), a responsável pela perpetuação da meritocracia como mecanismo definidor da posição ocupada por cada um nas classes sociais, encobrindo assim a determinação dos elementos que previamente condicionam a atuação dos agentes no cotidiano.

As ausências de auto-estima, de reconhecimento e de aprendizado familiar sobre papéis básicos da sociedade, segundo Souza (2006), impactam na capacidade de um sujeito se concentrar, se disciplinar, exercitar uma leitura, pensar prospectivamente e ser competitivo no mundo do trabalho. Estes, por sua vez, são exemplos de aspectos a serem considerados para compreender como se produzem e se reproduzem as classes e as desigualdades sociais para além das leituras economicistas e generalistas. Neste sentido, o autor sintetiza que esses fenômenos da realidade concreta devem ser compreendidos por meio do fio invisível, inconsciente e pré-reflexivo constituinte da ordem social vigente. Ordem esta que é a hierarquia 
D’Auria, B. B., Mezzaroba. C., \& Santos, S. M. dos. (2021, maio/ago.). Pertencimento à classe social e práticas corporais: revisando o tema na literatura e ensaiando relações possíveis

moral do desempenho, julgadora opaca e implícita do que se define ser útil e produtivo para a sociedade.

Não obstante, é a busca por compreender o entendimento do campo científico acerca do pertencimento à determinada classe social e a relação com as atividades físicas e esportivas de crianças e adolescentes - chamadas, aqui, em seu conjunto, de práticas corporais -, que se situa o objetivo deste trabalho. Realizamos, portanto, uma leitura das perspectivas apresentadas na literatura sobre o tema a partir do referencial de Jessé Souza sobre a questão de classe social. $\mathrm{Na}$ sequência do texto apresentamos os procedimentos metodológicos executados para a realização do estudo.

\section{Procedimentos metodológicos}

Embora consideremos o texto como um exercício ensaístico, para tal, realizamos uma revisão sistemática com base no protocolo Preferred Reporting Items for Systematic Reviews and Meta-Analyses (PRISMA) (Moher et al., 2016). Partimos dos resultados de uma revisão sistemática e das suas análises para exercitarmos o ensaio, a partir dos dados levantados, dialogando/articulando-os em relação às compreensões quanto às classes sociais.

Em relação à estratégia de busca dos artigos, ela foi realizada nas bases de dados Pubmed, Psycinfo, Scopus e Sportdiscus nos meses de março e abril de 2018. Todas essas bases são de grande abrangência na área da saúde e na temática específica do ensaio. Os descritores selecionados para a busca dos artigos foram definidos com a utilização do MeSH (Medical subject headings) e o DECS (Descritores em Ciências da Saúde). Após a definição das palavraschave e a forma de utilização dos operadores booleanos, a estratégia de busca foi: "social status" OR "social environment" OR "social class" OR "social determinants of health" OR “social problems” AND Sport OR volleyball OR basketball OR soccer OR swimming OR "team sports" OR handball OR boxing OR "martial arts" OR athletics.

Quanto aos critérios de inclusão e exclusão dos textos encontrados, para a seleção do estudo em questão, foram respeitados os seguintes critérios de inclusão: a) estudos relacionados à classe social e à prática esportiva por crianças e adolescentes; b) em língua portuguesa, inglesa ou espanhola. Os critérios de exclusão foram: a) estudos de revisão; b) dissertações, teses e capítulos de livros. Todas as etapas foram executadas por dois pesquisadores de forma independente, em que se estabelecia um consenso quanto aos resultados. Quando isso não foi possível, um terceiro pesquisador era chamado para uma decisão final. 
D’Auria, B. B., Mezzaroba. C., \& Santos, S. M. dos. (2021, maio/ago.). Pertencimento à classe social e práticas corporais: revisando o tema na literatura e ensaiando relações possíveis

\section{Apresentação dos resultados}

Na fase de identificação, os resultados encontrados na busca foram exportados para o Microsoft Excel (Microsoft Corporation, Redmond, EUA). Após realizada a busca nas bases de dados, foram encontrados 1027 artigos distribuídos da seguinte forma: Scopus (937), Sportdiscus (47), Pubmed (40) e Psycinfo (3). De todos os artigos encontrados, 60 foram removidos por serem duplicados. No processo de triagem, 802 textos foram excluídos na leitura do título e 84 excluídos na leitura do resumo, restando 81 artigos para a leitura na íntegra. No estágio de elegibilidade, 55 artigos foram excluídos por não atenderem critérios como o desenho do estudo, por não tratarem de classe social ou por não terem sido realizados com crianças e adolescentes. Dessa forma, restaram 26 estudos que fazem parte da amostra.

Dos 26 artigos, 25 foram publicados no período de 2003 a 2017. Os estudos usaram o design transversal e o de coorte. No total foram analisados 94.173 participantes, sendo que a faixa etária variou de 04 (quatro) a 18 (dezoito) anos. A maioria dos estudos foram realizados no continente europeu e na América do Norte, conforme podemos ver na figura 1.

Figura 1 - Distribuição geográfica das publicações mundiais sobre classe social e nível de atividade física

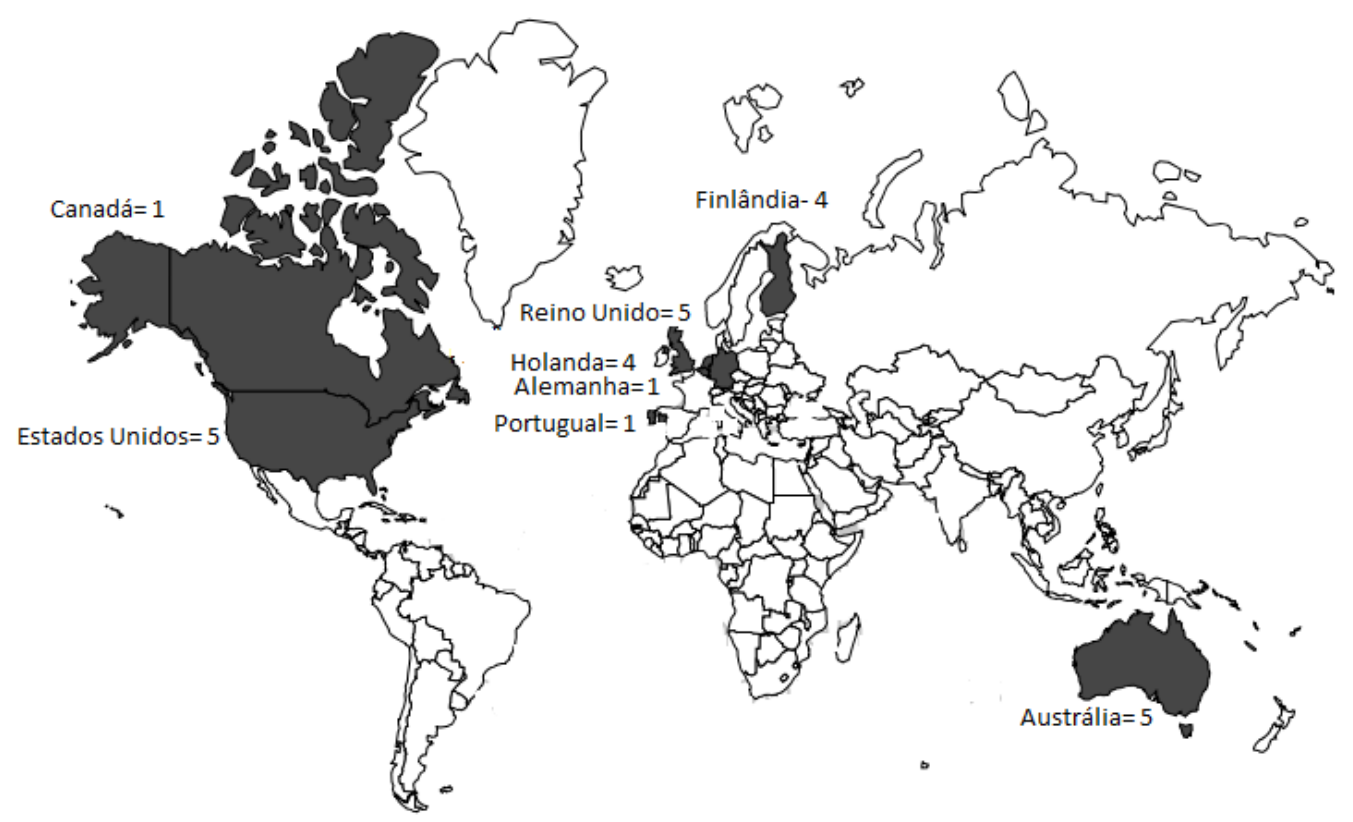

Fonte: Elaborada pelos próprios autores.

A principal variável analisada pelos estudos foi a classe social ou o status socioeconômico. No entanto, como se trata de conceitos que podem divergir entre os autores, 
D’Auria, B. B., Mezzaroba. C., \& Santos, S. M. dos. (2021, maio/ago.). Pertencimento à classe social e práticas corporais: revisando o tema na literatura e ensaiando relações possíveis

cada estudo optou por analisar outras variáveis que julgaram necessárias para entender a questão. Dessa maneira, para além da faixa de renda, observamos estudos que investigaram o nível educacional dos pais, a disponibilidade de espaços adequados para a prática de esportes e de lazer, a segurança dos bairros, sexo, comportamento sedentário e até mesmo o clima da região. Diante desse cenário, optamos em dividir os estudos em três grupos com base na frequência e significância que as variáveis apresentaram para os artigos. Dessa forma, 14 estudos tiveram como principal variável a classe social, 7 estudos focaram em analisar a constituição familiar e 5 estudos deram maior atenção ao nível de estrutura e segurança dos bairros.

Os resultados mostraram que crianças e adolescentes de classe social mais alta são mais ativos fisicamente e praticam mais esportes se comparado com crianças e adolescentes de classe social mais baixa. Conclui-se, nesse sentido, que a classe social é um fator que influencia o nível de atividade física nessa faixa etária (Fairclough et al., 2009; Sallis et al., 1996; Walters et al., 2008; Seabra et al., 2012; Hardy et al., 2007; Tammelin et al., 2003; Lampinen et al., 2017; Wijtzes et al., 2014; D’Haese et al., 2014).

A constituição familiar também aparece como um mediador no nível de prática de atividade física de crianças e adolescentes. Estudos demonstram que crianças e adolescentes que possuem irmãos praticam mais atividade física se comparado com crianças unigênitas (Gorely et al., 2009). Famílias em que os pais possuíam um alto nível educacional e praticavam atividade física com regularidade, exerceram influência positiva nos níveis de atividade física de seus filhos (Gorely et al., 2009; McMillan, Mcisaac \& Janssen, 2008; Eime et al., 2013; Brockman et al., 2009; Mutz \& Albrecht, 2017; Lampinen et al., 2017).

O nível de segurança dos bairros e a disponibilidade nestes de equipamentos e instalações adequadas tiveram influência na prática esportiva de crianças e adolescentes (Graham, Schneider \& Dickerson, 2011; Weir, Etelson \& Brand, 2006; De Jong et al., 2011; Jekauc et al., 2013; D’Haese et al., 2014). Paralelamente, identificou-se que durante o inverno crianças e adolescentes de classe social mais baixa diminuíram o volume de prática de atividade física (Hardy et al., 2007). Além disso, destacou-se que crianças obesas ou com excesso de peso e com menor nível socioeconômico, tendem a ter níveis mais baixos de atração por atividade física, menor percepção de competência física, menor suporte dos pais para a prática esportiva e possuem níveis mais altos de tempo gasto assistindo TV (Seabra et al., 2012).

O esporte está associado à autopercepção de popularidade para crianças e adolescentes independentemente do sexo e classe social (Shakib et al., 2011). Em determinado tempo e 
D’Auria, B. B., Mezzaroba. C., \& Santos, S. M. dos. (2021, maio/ago.). Pertencimento à classe social e práticas corporais: revisando o tema na literatura e ensaiando relações possíveis

espaço, meninos apresentaram maiores níveis de participação em aulas de Educação Física e de atividade física moderada e vigorosa do que as meninas (Sallis et al., 1996). A inatividade física, por sua vez, foi associada a sintomas ansiosos/deprimidos, sintomas retraídos/deprimidos, problemas sociais, problemas de pensamento e problemas de atenção em meninos. Nas meninas a inatividade física foi associada a sintomas retraídos/deprimidos, queixas somáticas, problemas sociais, problemas de atenção e comportamento de quebrar regras (Kantomaa et al., 2007).

O conjunto de dados revisados na literatura sinalizam que pertencer a um grupo social de maior poder aquisitivo possibilita experienciar mais práticas corporais, podendo desenvolvêlas em segurança no lugar onde se mora. Por outro lado, não é possível sinalizar se tais práticas apresentam diferenciação por pertencimento de classe, embora a percepção sobre corpo e práticas corporais seja influenciada por pais e mães que têm maior nível de instrução.

Praticamente todos os estudos incluídos na revisão analisaram mais de uma variável para tentar explicar o nível de atividade física de crianças e adolescentes. Além da classe social, foram analisados o nível de escolaridade e de prática esportiva dos pais (Gorely et al., 2009; McMillan, Mcisaac \& Janssen, 2008; Eime et al., 2013; Brockman et al., 2009; Mutz \& Albrecht, 2017; Lampinen et al., 2017), características de bairros (Graham, Schneider \& Dickerson, 2011; Weir, Etelson \& Brand, 2006; De Jong et al., 2011; Jekauc et al., 2013; D’Haese et al., 2014), constituição familiar, sexo, status de peso das crianças e dos adolescentes e o clima (Hardy et al., 2007; Seabra et al., 2012; Shakib et al., 2011; Sallis et al., 1996; Kantomaa et al., 2007).

O impacto que o bairro ou a área residencial exercem sobre o nível de atividade física de crianças e adolescentes foi investigado por cinco estudos. Todos estes fizeram comparação entre regiões/bairros de diferentes estratos sociais com crianças e adolescentes de ambos os sexos. Graham, Schneider e Dickerson (2011), por exemplo, concluíram que crianças e adolescentes que moram em regiões que tinham melhor estrutura esportiva, praticavam mais esporte e tinham mais apoio familiar se comparado com aqueles que moram em regiões menos estruturadas.

Destacamos, neste sentido, que o bairro ou área residencial também indicam pertencimento de classe. Ou seja, assim como o vestuário/indumentária diz muito de nós, enquanto corpos/agentes, nossas casas dizem muito de nós sobre nossos corpos coletivos/famílias, e de uma homogeneização distribuída num dado espaço social, que explicita proximidades econômicas, não necessariamente culturais. Tal dado configura-se como 
D’Auria, B. B., Mezzaroba. C., \& Santos, S. M. dos. (2021, maio/ago.). Pertencimento à classe social e práticas corporais: revisando o tema na literatura e ensaiando relações possíveis

importante, pois embora pareça constatar o “óbvio", este óbvio necessita ser estranhado, no sentido de que quando o espaço é convidativo, com oferta de equipamentos para desenvolver práticas corporais, as relações de mobilidade e de cuidados corporais também são outras.

Já no estudo desenvolvido por Weir, Etelson e Brand (2006), os pesquisadores compararam o nível de ansiedade dos pais e sua percepção de segurança em relação aos bairros de diferentes classes sociais e concluíram que os pais que residiam em bairros de classe social mais baixa apresentaram um maior nível de ansiedade. Além disso, observou-se que seus filhos apresentavam níveis mais baixos de prática de exercício físico se comparado com crianças residentes em bairros de classes sociais mais altos.

Três artigos identificaram a influência da constituição familiar no nível de atividade física de crianças e adolescentes (Gorely et al., 2009; McMillan, Mcisaac \& Janssen, 2008; Eime et al., 2013). O estudo de Gorely et al. (2009) analisou a influência de circunstâncias familiares nos níveis de prática de atividade física e de comportamento sedentário em adolescentes. Foi identificado que meninos de mães solteiras passam mais tempo em comportamentos sedentários se comparado com famílias tradicionais. Além disso, observou-se que meninos com irmãos eram mais ativos fisicamente do que meninos que eram filhos únicos e meninas de baixo status socioeconômico passavam mais tempo assistindo TV se comparado com meninas de status social mais alto.

Observamos, então, Gorely et al. (2009) elucidarem a determinação de questões familiares na questão da classe social. Ao constatarem que adolescentes de pais solteiros e de status mais baixo assistem mais televisão e possuem uma probabilidade maior de comportamento sedentário, vemos não apenas a falta de acesso a espaços culturais e de lazer influenciarem os mesmos a ficarem em casa. Visualizamos nestes dados, por exemplo, a reconfiguração da organização familiar exigir que muitos desses adolescentes trabalhem para contribuir não só com renda, mas também com os cuidados da casa (lavar, fazer almoço, cuidar dos irmãos mais novos etc), faltando-lhes, por vezes, tempo ou disposição para as práticas corporais.

O estudo de McMillan, Mcisaac e Janssen (2008) analisou a estrutura familiar não tradicional, em que os acordos de custódia física são associados à participação de prática esportiva organizado na juventude. Os resultados indicaram que a riqueza familiar teve significativa influência na prática esportiva de crianças e adolescentes. Os meninos e meninas de famílias reconstituídas com visitação irregular de um segundo genitor, e famílias monoparentais com visitação regular de um segundo pai eram menos propensos a participar de 
D’Auria, B. B., Mezzaroba. C., \& Santos, S. M. dos. (2021, maio/ago.). Pertencimento à classe social e práticas corporais: revisando o tema na literatura e ensaiando relações possíveis

esportes organizados do que aqueles de famílias tradicionais. Corroborando com esses dados, Eime et al. (2013) verificaram que maior nível de participação em clubes esportivos por crianças está relacionado a terem pais inseridos no mercado de trabalho, com alto nível educacional e que oferecem maior estímulo aos filhos para a prática esportiva. Em comum, os estudos mostraram que crianças e adolescentes de famílias em que ambos os pais trabalham e somam os seus salários, conseguem oferecer melhores condições para que seus filhos atinjam níveis mais altos de prática de atividade física.

De Jong et al (2011) e Jekauc et al (2013) constataram que características demográficas agregadas à estrutura familiar mediaram o nível de atividade física de crianças e adolescentes, em que crianças de bairros mais pobres estavam mais suscetíveis à obesidade e tinham menores níveis de prática esportiva. Com relação à influência do peso corporal sobre o nível de atividade física, houve dois estudos que apontaram resultados nessa direção. Ambos investigaram além do IMC - Índice de Massa Corporal, outros fatores como nível socioeconômico e estilo de vida.

Seabra et al. (2012) investigaram a atração de crianças por atividade física e constataram que meninas, crianças obesas e com menor nível socioeconômico apresentaram menor atração por atividade física, menor apoio familiar e menor competência física. De Young (2011) investigou a influência de características pessoais e demográficas no excesso de peso de crianças e constatou que em bairros de classe social mais baixa, as crianças tinham maus hábitos alimentares e maior tempo gasto assistindo TV. O excesso de peso dessas crianças foi significativamente maior se comparado com crianças de bairros de classe social mais alta. Isso evidencia a relação existente entre menor poder aquisitivo com um menor acesso a espaços de prática de atividade física, formação mais deficitária e, consequentemente, menos contato com conhecimento sobre hábitos alimentares, questões de higiene e importância das práticas corporais para a vida humana.

Apesar de o clima não ter sido uma variável muito investigada, o estudo de Hardy et al. (2007) demonstrou que existe uma influência desta variável no nível de atividade física de adolescentes. Analisando fatores sazonais junto com fatores econômicos, os resultados mostraram que durante o inverno o nível de atividade física de adolescentes de classe social mais alta se manteve estável, enquanto que houve uma diminuição em adolescentes de classe social mais baixa. 
D’Auria, B. B., Mezzaroba. C., \& Santos, S. M. dos. (2021, maio/ago.). Pertencimento à classe social e práticas corporais: revisando o tema na literatura e ensaiando relações possíveis

Discussão dos dados: reflexões sobre classe social e níveis de atividade física e esporte a partir da sociologia da reprodução

O primeiro dado a ser discutido e refletido é o fato de os estudos identificados em nosso mapeamento terem sido desenvolvidos exclusivamente em países do chamado "primeiro mundo" ou do hemisfério norte, com exceção da Austrália. Antes de qualquer reflexão a ser deduzida da conjunção deles, importa destacar a inviabilidade de reprodução metodológica destes trabalhos, ou mesmo de associação analítica dos dados encontrados, em relação às realidades como a brasileira, a latinoamericana, a africana e até a asiática. Isto se deve, sobretudo, pelo fato de a configuração das classes sociais nos respectivos contextos ocorrerem de modo muito peculiar, vinculada, principalmente, aos processos de modernização de cada sociedade. Ademais, como em Souza (2003; 2005a), é preciso reconhecer e não desconsiderar a distinção da decorrência de tais processos, em especial, nos países e continentes centrais da modernidade (Europa e América do Norte), em comparação com aqueles periféricos, marginais a esta mesma modernidade.

O mecanismo de distinção social, segundo Souza (2003, p. 72), basicamente se define pela "[...] efetiva disseminação da noção de dignidade do agente racional que o torna agente produtivo e cidadão pleno". Para o autor, nas regiões centrais da modernidade tal distintivo é largamente difundido e os casos em que não ocorre são pontualmente marginais. Por outro lado:

Em sociedades periféricas como a brasileira, o habitus precário, que implica a existência de redes invisíveis e objetivas que desqualificam os indivíduos e grupos sociais precarizados como subprodutores e subcidadãos, e isso, sob a forma de uma evidência social insofismável, tanto para os privilegiados como para as próprias vítimas da precariedade, é um fenômeno de massa e justifica minha tese de que o que diferencia substancialmente esses dois tipos de sociedades é a produção social de uma "ralé estrutural" nas sociedades periféricas (Souza, 2003, p. 72).

Sob o entendimento das diferenças configurativas das classes sociais nas regiões centrais e periféricas da modernidade, portanto, destacamos como importante ter-se clareza da impossibilidade de os estudos mapeados no presente trabalho serem replicados, do ponto de vista teórico-prático, para o desenvolvimento do tema em contextos marginais da modernização do mundo. Evidenciamos, desse modo, que a correlação das práticas corporais (práticas de atividades físicas e esportivas) por crianças e adolescentes, considerando a questão de classe, quando observada em contextos da periferia global, como o brasileiro, deve levar em consideração outros indicadores sócio-históricos, mais complexos e implícitos, principalmente 
D’Auria, B. B., Mezzaroba. C., \& Santos, S. M. dos. (2021, maio/ago.). Pertencimento à classe social e práticas corporais: revisando o tema na literatura e ensaiando relações possíveis

das dinâmicas internas próprias, as quais revelam singularidades, heterogeneidades culturais, econômicas e sociais, mas, sobremaneira, desigualdades. Casos como esse certamente terão variáveis inexistentes em países como aqueles onde os estudos foram desenvolvidos. São índices, inclusive, provocados muitas das vezes por parâmetros de desempenho e produtividade estabelecidos por estes mesmos estados-nações centrais da modernização global.

Outro aspecto a ser destacado dos trabalhos revisados é que o denominador comum deles para o entendimento de classe social é a faixa de renda, o que indica uma leitura preponderantemente economicista da questão. Essa visão é, exatamente, uma forma interpretativa mantenedora da reprodução das classes, tanto das "classes populares", como das ditas "privilegiadas", pois não ajuda a desnudar os problemas concretos da discussão e, em grande medida, subliminares aos parâmetros econômicos (Souza, 2014). Conforme sustenta Souza (2013b, p. 55), “[...] O economicismo é a redução das relações sociais à sua dimensão 'econômica' e 'material'", sendo que as classes sociais não podem ser reduzidas a faixas de renda, tampouco a ocupação profissional como definidora do lugar do agente na sociedade.

Ainda que os trabalhos tenham buscado e identificado variáveis analíticas correlacionadas às faixas de renda, - as quais discutiremos a seguir -, ao adotarem o elemento financeiro como balizador teórico-metodológico e associá-lo à organização das classes sociais, os estudos incorrem no equívoco, criticado por Souza (2014, p. 36) ao analisar outras situações, de pressupor que "[...] a simples determinação das faixas de renda esclarece o comportamento prático dos indivíduos”. O autor ainda complementa: “A 'cegueira' do economicismo é, portanto, dupla: ela é cega em relação aos aspectos decisivos que reproduzem todos os privilégios e é cega, também, em relação à falsa justificação social de todos os privilégios" (Souza, 2014, p. 37).

Souza (2013b) considera, então, que é necessário operar inter-relações com outros capitais, além do "capital econômico", para pensarmos quanto às classes sociais, pois a distinção social não se dá de maneira unívoca pela questão econômica. Embora esta se destaque e seja determinante, também devem ser levadas em consideração as questões simbólicas (como o capital cultural, por exemplo, que para Bourdieu, é aquilo que logramos "aprender" - e aqui situemos a aprendizagem das práticas corporais como formas distintivas de marcar e demarcar corpos em suas posições sociais), valorativas e moralistas, bastante presentes e valorizadas nas sociedades. Afirma Souza (2013b, p. 56), que é preciso: "incluir tudo aquilo que passa a ser decisivo para assegurar o acesso privilegiado a todos os bens e recursos escassos em disputa na competição social.” 
D’Auria, B. B., Mezzaroba. C., \& Santos, S. M. dos. (2021, maio/ago.). Pertencimento à classe social e práticas corporais: revisando o tema na literatura e ensaiando relações possíveis

Segundo Souza (2014), por conseguinte, é importante não nos restringirmos simplesmente ao capital econômico como fator determinante das classes, mas sim levarmos em consideração o capital cultural e o capital social acumulados, ou seja, aqueles capitais possíveis de serem mobilizados pelas diferentes parcelas da sociedade nas suas atitudes e comportamentos cotidianos. A ideia, nesse sentido, é considerar o processo de incorporação de determinados modos de se comportar e agir das camadas da sociedade, compreender os processos do "tornar-se corpo" das diferentes classes, superando assim "[...] a oposição entre corpo e espírito, na qual o corpo é pensado como 'matéria sem vida' e sem 'espírito', em favor de uma concepção pela qual o corpo é compreendido como um 'emissor de sinais' e como prenhe de significados sociais" (Souza, 2014, p. 37).

Se a principal característica que distingue as classes sociais, segundo Souza (2006), é a apropriação privilegiada de "capital cultural”, seja ele técnico, artístico ou literário, os fatores associados a elas, mapeados pelos trabalhos, nos permitem observar ali indícios de um aprofundamento a aspectos implícitos, possivelmente interferentes, da prática de exercício físico e de esportes por crianças e adolescentes. As variáveis de estrutura familiar, nível de escolaridade de pais e mães, arquitetura urbana dos bairros e fatores climáticos dos locais onde se reside, bem como o sexo das crianças e adolescentes, são componentes considerados pelos trabalhos revisados e que, por exemplo, contribuem para a ampliação do debate sobre classes sociais na relação com o tema em específico.

Retomemos uma ampla análise de Souza (2013b) que ilustra nossas reflexões aqui empreendidas:

Os filhos das classes médias, com grande probabilidade, possuem esses "estímulos" emocionais e afetivos, ou seja, esse "capital familiar" que é sempre um privilégio de classe e a base de qualquer capital cultural valorizado, o que irá garantir a sua reprodução de classe, como "classe privilegiada" em dois sentidos. Em primeiro lugar, vão chegar como "vencedores" na escola, depois no mercado de trabalho, e ocupar espaços que as "classes populares" - a classe trabalhadora nos seus diversos segmentos e a "ralé" dos excluídos sociais - não poderão alcançar; em segundo lugar, reproduzem também a "invisibilidade" do processo social de produção de privilégios - que se realizam na privacidade dos lares - e que podem "aparecer", posto que sua gênese é encoberta, como "mérito individual" e, portanto, como "merecimento" dos fillhos das classes médias (Souza, 2013b p. 58).

De acordo com o nosso mapeamento, a constituição familiar exerce influência no nível de atividade física de crianças e jovens (Gorely et al., 2009; McMillan, Mcisaac \& Janssen, 2008; Eime et al, 2013). Nos termos de Souza (2006), essa questão se explica na medida em que famílias de maior poder aquisitivo possuem uma socialização familiar privilegiada, com 
D’Auria, B. B., Mezzaroba. C., \& Santos, S. M. dos. (2021, maio/ago.). Pertencimento à classe social e práticas corporais: revisando o tema na literatura e ensaiando relações possíveis

pais que possuem melhores condições de exercer exemplos efetivos, se comparado com famílias de classe social mais baixa, e, portanto, contribuem assim para a construção (ou não) de uma disposição de leitura, compreensão e disciplinamento para as diversas práticas corporais (sob a forma de prática de exercício físico desde os primeiros anos de vida, por exemplo, e que vão tomando outras formas no desenrolar das etapas do desenvolvimento dessas crianças). Para as famílias de estrato social mais baixo, por sua vez, a escolarização precária, as péssimas condições de trabalho e a ausência de tempo livre dos pais são marcas do abandono social (Souza, 2006), as quais dificultam e funcionam como barreiras simbólicas para a existência de exemplos afetivos, no ambiente familiar, que sejam geradores de mudança individual e social de comportamentos, neste caso, por exemplo, de prática de atividades físicas e esportivas.

Consideramos relevante destacar, neste momento, a contribuição do olhar sociológico para o entendimento do fenômeno das relações explícitas e, sobretudo, implícitas entre as práticas corporais e as classes sociais. É tal exercício crítico-reflexivo que nos permite pensar "leis sociais gerais" sobre aquilo que é naturalizado por simplesmente se pertencer a uma ou outra classe social. Ou seja, ainda que estejamos aqui observando e refletindo a especificidade das práticas corporais manifestas nos estratos da sociedade, compreendê-las sob a perspectiva de leitura da lógica das relações sociais nos permite estabelecer parâmetros mais concretos do que efetivamente determina e influencia no exercício (ou não) de práticas corporais.

O abandono social, fator estruturante das classes sociais mais baixas (Souza, 2006), repercute não apenas no ambiente familiar, mas de acordo com os estudos mapeados, se expressa também em espaços públicos e infraestrutura necessária para a prática de esportes e de lazer (Graham, Schneider \& Dickerson, 2011; Weir, Etelson \& Brand, 2006; De Jong et al., 2011; Jekauc et al., 2013; D’Haese et al., 2014). Refletido em péssimas condições de moradia e bairros que não dispõem de estrutura e nem segurança para um convívio entre as pessoas, tal abandono acaba por transferir a responsabilidade do acesso às práticas corporais (compreendendo o exercício físico, o esporte e as práticas do lazer) para a iniciativa privada. Como consequência, restringe-se e precariza esse modo de agir e de se comportar para as pessoas de classe social mais baixa, as quais não conseguem pagar por esse tipo de serviço e, por fim, são revertidas em indicadores populacionais negativos de estudos epidemiológicos sobre prática de atividade física e comportamento sedentário.

Os trabalhos que se propõem a identificar as diferenças de níveis de práticas de atividades físicas e esportivas de crianças e adolescentes de acordo com o sexo (Sallis et al., 1996; Walters et al., 2008; Fairclough et al., 2009; Shakib et al., 2011; Seabra et al., 2012; 
D’Auria, B. B., Mezzaroba. C., \& Santos, S. M. dos. (2021, maio/ago.). Pertencimento à classe social e práticas corporais: revisando o tema na literatura e ensaiando relações possíveis

Eime et al., 2013; Payne; Townsend \& Foster, 2013), apontaram principalmente as diferenças entre os tipos de esporte e exercício físico que são praticados por ambos os grupos, bem como os diferentes espaços que cada um acaba frequentando. Isso contribui fortemente para a constatação de interveniência desta variável e complexificação do debate sobre classe neste contexto. Entretanto, por si só, esse não é um marcador social autoexplicativo. Ele demanda um aprofundamento sócio-histórico sobre as questões de gênero, de modo que seja possível desvelar, por exemplo, como se constitui o gosto pelas práticas de atividades físicas e esportivas, bem como de modalidades específicas, no decorrer das dinâmicas da sociedade em seu processo. Ou seja, as pesquisas revelam o quanto ainda na infância é possível se identificar como o universo das práticas corporais manifestam uma maneira de ser e estar no mundo, desde criança, simplesmente pelo ato de mobilizar seu corpo para brincar, jogar, praticar esportes e exercícios. Todavia, para além das ideias de liberdade e espontaneidade do brincar e jogar, aqui é importante destacar como os meninos conseguem ter suas práticas corporais de maneira mais livre, se comparado ao grupo de meninas.

Souza (2013b) comenta, quanto ao capital social de relações sociais, que "É este capital que permite aquele amálgama específico entre 'interesses e afetos', tão importantes para a gênese e reprodução das amizades, casamentos e alianças de todo tipo no interior de uma classe, onde a reprodução dos direitos de propriedade é tão decisiva." (Souza, 2013b, p. 5). Meninos e meninas - em certos contextos - têm possibilidades distintas quanto a este capital social de relações sociais!

Com base na perspectiva bourdieusiana de habitus, Souza (2004) disserta:

Como a distinção social baseada no gosto não se limita aos artefatos da cultura legítima, mas abrange todas as dimensões da vida humana que implicam alguma escolha - vestuário, comida, formas de lazer, opções de consumo etc. -, o gosto funciona como o sentido de distinção por excelência, permitindo separar e unir pessoas e, conseqüentemente, forjar solidariedades ou constituir divisões grupais de forma universal (tudo é gosto!) e invisível. (Souza, 2004, p. 85).

Sob essa ótica, por conseguinte, ressaltamos como o olhar epidemiológico para as diferenças de práticas corporais por sexo acaba maquiando o dispositivo social do gosto e, principalmente, o processo constituinte desse mecanismo de distinção. Investigações sobre o "como" e o "porquê" de determinado comportamento e modo de agir esportivamente de uma menina ou de um menino tornam-se, nesse sentido, de suma importância para qualificar o debate sobre classe social deste tema. Acompanhando o pensamento de Souza (2003), essa é 
D’Auria, B. B., Mezzaroba. C., \& Santos, S. M. dos. (2021, maio/ago.). Pertencimento à classe social e práticas corporais: revisando o tema na literatura e ensaiando relações possíveis

uma forma interpretativa que poderia retirar da opacidade a moeda invisível que é o gosto e a moralidade, existentes em torno da prática de esporte, por exemplo, para melhor esclarecer esta variável do sexo.

Por fim, ainda que a variável climática não tenha uma ocorrência expansiva nos estudos, mais uma vez é possível visualizarmos como o olhar para a questão do pertencimento de classe se detém a parâmetros objetivos do problema. A constatação de que adolescentes de faixas de renda mais altas, quando no período de inverno, praticam mais atividades físicas e esportivas do que jovens de camadas mais baixas no contexto australiano, não revela, por exemplo, como ocorreram esses distintos processos de inscrição nos corpos (Souza, 2004) do hábito (ou a falta) de se praticar exercícios mesmo em períodos climáticos adversos.

\section{Conclusão}

Pensar os conceitos de classe social e do "efeito de distinção" para compreender como eles influenciam não apenas o acesso, mas também o "gosto" por determinadas práticas corporais, auxiliaram no melhor entendimento dos mecanismos sociais diversos intervenientes nesse fenômeno em questão. Com base na sociologia da reprodução, vimos neste trabalho como o "gosto" é construído e determinado socialmente e como o fato de se pertencer a uma determinada classe social já significa ter acesso (ou não) a determinadas práticas corporais.

Por meio dos achados do estudo empreendido, destacamos a predominância da perspectiva economicista na definição do conceito e na abordagem da classe social como categoria ou variável analítica correlacionada aos níveis de práticas corporais de crianças e adolescentes. Contudo, ao mesmo tempo, observamos na literatura mapeada algumas tendências de ampliação do entendimento de classe, que a considera e a analisa para além dos parâmetros financeiros como faixa de renda, principalmente abordando-a sob o ponto de vista da constituição familiar e das condições de segurança e estrutura dos bairros onde os diferentes grupos sociais vivem. Sob a ótica da sociologia da reprodução aqui mobilizada, reiteramos como fundamental esta ampliação de paradigma, pois a estratificação das sociedades se definem não só pelo capital econômico, mas também pelos capitais culturais e sociais dispostos e distribuídos em cada contexto vivido, não sendo diferente, por conseguinte, com o fenômeno das práticas corporais (acesso, gosto, espaços, possibilidades, consumos paralelos etc.).

Reiteramos, nos termos de Souza (2013b, p. 64), que: 
D’Auria, B. B., Mezzaroba. C., \& Santos, S. M. dos. (2021, maio/ago.). Pertencimento à classe social e práticas corporais: revisando o tema na literatura e ensaiando relações possíveis

A forma como o pertencimento de classe constrói, tanto material quanto simbolicamente, indivíduos distintamente aparelhados para todos os desafios da competição social, é para mim o ponto mais central para uma teoria verdadeiramente crítica da realidade social. Ela é também o verdadeiro esclarecimento do "mistério" de nossa abissal desigualdade (Souza, 2013b, p. 64).

Diante do cenário descrito e vislumbrado aqui neste trabalho, ressaltamos a importância de refletirmos também sobre a legislação brasileira, especificamente no que se refere ao fato de o direito à prática esportiva ser de cunho individual e não social (direito coletivo). Entendemos que este caráter individualizado, por sua vez, acaba por gerar uma responsabilização (e comportamentalização) dos sujeitos para que se predisponham a um determinado tipo de gosto, neste caso, pelas práticas esportivas. Como visto, não podemos desconsiderar que o gosto é uma questão de classe, fenômeno distintivo, portanto não sendo apenas uma disposição individual. Neste sentido, considerando a relevância das práticas corporais como expressão sociocultural da vida humana e como forma de promoção da saúde coletiva, compreendemos como candente repensarmos tais práticas como direitos sociais universais de todas e todos a serem garantidos pelo Estado.

A compreensão crítica aqui desenvolvida sobre as questões de classe e a relação com as práticas corporais também contribui para a elaboração e aprimoramento de políticas públicas para a promoção e garantia do acesso às práticas corporais. De tal modo, sugerimos aos agentes políticos, principalmente ao Estado brasileiro, se aterem não somente a indicadores demográficos como o Índice de Desenvolvimento Humano (IDH), mas também a questões simbólicas e implícitas, que exercem forte influência e, por vezes, são determinantes na possibilidade de criação (ou não) de hábitos dos cidadãos e cidadãs para o exercício de práticas corporais.

O presente artigo permite que futuros estudos, seja de base teórica, ou documental, ou mesmo do tipo empírico, se debrucem, a partir de nossas reflexões, em pensar e, inclusive, experimentar possibilidades que envolvam o entrelaçamento do entendimento ampliado de classe social, com a proposição e avaliação de políticas públicas e a oferta de práticas corporais nos vários contextos brasileiros. Assim, ações gerenciais voltadas para a finalidade de tais práticas poderão se pautar em conhecimentos cientificamente respaldados e se aproximar da complexidade que configura a questão de classe social no cenário contemporâneo. A título de exemplo, pode-se propor ações, políticas ou programas de práticas corporais para crianças e adolescentes, balizadas em diferentes aspectos distintivos da condição social, tais como: i) os tempos livres e tempos de trabalho dos familiares responsáveis, considerando a multiplicidade 
D’Auria, B. B., Mezzaroba. C., \& Santos, S. M. dos. (2021, maio/ago.). Pertencimento à classe social e práticas corporais: revisando o tema na literatura e ensaiando relações possíveis

de formatos de composição familiar, em especial aquelas de filhos e filhas de mães solteiras; ii) os horários do transporte público que chega e parte dos locais de desenvolvimento das propostas; iii) a localização comunitária das ações, de modo a encontrar ou produzir espaços de pertencimento e de sentimento de segurança para que o público alvo sinta-se convidado a aderir e a desenvolver o gosto pelas práticas corporais. Entendemos, deste modo, que estas são pistas para que o fenômeno das práticas corporais, configurado como mecanismo de distinção de classes, possa começar a ser minimizado em diferentes realidades.

\section{Referências}

Alves Junior, D. (2008). A relação mídia-esporte: um estudo das mensagens esportivas na televisão e seus efeitos na prática de Educação Física escolar, na percepção do professor. 86f. Dissertação de Mestrado - UNB, Brasília. Recuperado em 26 de abril de 2021. [https://repositorio.unb.br/handle/10482/1086].

Boltanski, L. (2004). As classes sociais e o corpo. $3^{\mathrm{a}}$. ed. São Paulo: Paz e Terra. Brockman, R. et al (2009). "Get off the sofa and go and play": Family and socioeconomic influences on the physical activity of 10-11 year old children. BMC public health, 9(253): 1-7. https://doi.org/10.1186/1471-2458-9-253.

Carson, V. et al (2016). Systematic review of sedentary behaviour and health indicators in school-aged children and youth: an update. Canadian Science Publishing, 41(6): 241-265. https://doi.org/10.1139/apnm-2015-0630.

Colley, R. C. et al (2013). The association between accelerometer-measured patterns of sedentary time and health risk in children and youth: results from the Canadian Health Measures Survey. BMC Public Health, 13(200): 2-9. https://doi.org/10.1186/1471-2458-13200.

Coutinho, D. \& Barros, R. P. (2013). Quem precisa de uma definição de classe média? In: Fundação Perseu Abramo \& Fundação Friedrich Ebert (org.). Classes? Que classes? Ciclo de Debates sobre Classes Sociais. São Paulo: Editora Fundação Perseu Abramo, p. 125138.

De Jong, E. et al (2011). Behavioural and socio-demographic characteristics of Dutch neighbourhoods with high prevalence of childhood obesity. International Journal of Pediatric Obesity, 6(3-4): 298-305. https://doi.org/10.3109/17477166.2011.583659.

D'Haese, S. et al (2014). The association between objective walkability, neighborhood socioeconomic status, and physical activity in Belgian children. International Journal of Behavioral Nutrition and Physical Activity, 11(1): 2-8. https://doi.org/10.1186/s12966-0140104-1. 
D’Auria, B. B., Mezzaroba. C., \& Santos, S. M. dos. (2021, maio/ago.). Pertencimento à classe social e práticas corporais: revisando o tema na literatura e ensaiando relações possíveis

Donnelly, J. E. et al (2016). Physical Activity, Fitness, Cognitive Function, and Academic Achievement in Children: A Systematic Review. Medicine Science Sport and Exercise, 8(48): 1197-1222. https://dx.doi.org/10.1249\%2FMSS.0000000000000901.

Eime, R. M. et al (2013). Family support and ease of access link socio-economic status and sports club membership in adolescent girls: a mediation study. International Journal of Behavioral Nutrition and Physical Activity, 10(1): 2-12. https://doi.org/10.1186/1479-5868$10-50$.

Fairclough, S. J. et al (2009). Associations between children's socioeconomic status, weight status, and sex, with screen-based sedentary behaviours and sport participation.

International Journal of Pediatric Obesity, 4(4): 299-305.

https://doi.org/10.3109/17477160902811215.

Fogelholm, M. (2010). Physical activity, fitness and fatness: relations to mortality, morbidity and disease risk factors. A systematic review. Obesity reviews, 11(1): 202-221. https://doi.org/10.1111/j.1467-789X.2009.00653.x.

Fraga, A. B.; Carvalho, Y. M. \& Gomes, I. M. (2012). Políticas de formação em educação física e saúde coletiva. Trabalho, Educação e Saúde, Rio de Janeiro, 10(3): 367-386. https://doi.org/10.1590/S1981-77462012000300002.

Glaner, M. F. (2003) A importância da aptidão física relacionada à saúde. Revista Brasileira de Cineantropometria \& Desempenho Humano, 5(2): 75-85. https://doi.org/10.1590/\%25x.

Gonçalves, M. B \& Franco, N. (2016). Sedentarismo na adolescência e fatores determinantes. Journal Health NPEPS, 1(2): 263-277. Recuperado em 26 de abril de 2021. https://periodicos.unemat.br/index.php/jhnpeps/article/view/1590.

Gorely, T. et al (2009). Family circumstance, sedentary behaviour and physical activity in adolescents living in England: Project STIL. International Journal of Behavioral Nutrition and Physical Activity, 6(33): 1-8. https://doi.org/10.1186/1479-5868-6-33.

Graham, D. J; Schneider, M \& Dickerson, S (2011). Environmental resources moderate the relationship between social support and school sports participation among adolescents: a cross-sectional analysis. International Journal of Behavioral Nutrition and Physical Activity, 8(34): 2-10. https://doi.org/10.1186/1479-5868-8-34.

Gualano, B \& Tinucci, T. (2011). Sedentarismo, exercício físico e doenças crônicas. Revista Brasileira de Educação Física e Esportes, 24(1): 37-43. https://doi.org/10.1590/\$180755092011000500005.

Hardy, L. L. et al (2007). Physical activity among adolescents in New South Wales (Australia): 1997 and 2004. Official Journal of the American College of Sports Medicine, 40(5): 835841. https://doi.org/I0.1249/MSS.0b013e318163f286.

Instituto Brasileiro de Geografia e Estatística (2016). Pesquisa nacional por amostra de domicílio. Rio de Janeiro: CDDI. 
D’Auria, B. B., Mezzaroba. C., \& Santos, S. M. dos. (2021, maio/ago.). Pertencimento à classe social e práticas corporais: revisando o tema na literatura e ensaiando relações possíveis

Jekauc, D. et al (2013). Physical activity in sports clubs of children and adolescents in Germany: Results from a nationwide representative survey. Journal of public health, 21(6): 505-513. https://doi.org/10.1007/s10389-013-0579-2.

Jung, K. W. et al (2013). Cancer statistics in Korea: incidence, mortality, survival and prevalence in 2010. Cancer research and treatment: official journal of Korean Cancer Association, 45(1), 1. https://dx.doi.org/10.4143\%2Fcrt.2013.45.1.1.

Kantomaa, M. T. et al (2007). Adolescents' physical activity in relation to family income and parents' education. Preventive Medicine, 44(5): 410-415.

https://doi.org/10.1016/j.ypmed.2007.01.008.

Lampinen, E. K. et al (2017). Physical activity, sedentary behaviour, and socioeconomic status among Finnish girls and boys aged 6-8 years. European jornal of sports Science, 17(4): 462472. https://doi.org/10.1080/17461391.2017.1294619.

Lazzarotti Filho, A. et al (2010). O termo práticas corporais na literatura científica brasileira e sua repercussão no campo da Educação Física. Movimento, Porto Alegre, 16(1): 11-29. https://doi.org/10.22456/1982-8918.9000.

Lee, I. M. et al (2012). Effect of physical inactivity on major non-communicable diseases worldwide: an analysis of burden of disease and life expectancy. The lancet, 380(9838), 219-229. https://doi.org/10.1016/S0140-6736(12)61031-9.

Lopes, F. (2014). Esporte e classe social na sociologia de Pierre Bourdieu. Revista Espaço Ética: Educação, Gestão e Consumo, 1(3): 168-182. Recuperado em 29 de março de 2017. http://revistaespacoetica.com.br/wpcontent/uploads/2015/01/168a182_revistaEE03_FelipeLopes.pdf.

McMillan, R.; Mcisaac, M \& Janssen, I. (2016). Family structure as a correlate of organized sport participation among youth. Plos One, 10(2): 2-12.

https://doi.org/10.1371/journal.pone.0147403.

Moher, D. et al (2016). Ítems de referencia para publicar Protocolos de Revisiones Sistemáticas y Metaanálisis: Declaración PRISMA-P 2015. Revista Española de Nutrición Humana y Dietética, 20(2), 148-160. http://dx.doi.org/10.14306/renhyd.20.2.223.

Mutz, M. \& Albrecht, P. (2017). Parents' Social Status and Children's Daily Physical Activity: The Role of Familial Socialization and Support. Journal of Child and Family Studies, 26(11): 3026-3035. https://doi.org/10.1007/s10826-017-0808-3.

Payne, S.; Townsend, N. \& Foster, C. (2013). The physical activity profile of active children in England. International Journal of Behavioral Nutrition and Physical Activity, 10(16): 28. https://doi.org/10.1186/1479-5868-10-136.

Rojas; G. G.; Grinszpun, M. \& Seid, G. (2010). Clases de deporte y deportes de classe. La distribución de los gustos y prácticas deportivas en el espacio social. In: Jornadas De Sociologia De La Universidad Nacional De La Plata, 7, La Plata. Anais... La Plata. 
D’Auria, B. B., Mezzaroba. C., \& Santos, S. M. dos. (2021, maio/ago.). Pertencimento à classe social e práticas corporais: revisando o tema na literatura e ensaiando relações possíveis

Recuperado em 23 de março de 2017.

http://www.memoria.fahce.unlp.edu.ar/library?a=d\&c=eventos\&d=Jev1990.

Sallis, J. F. et al (1996). Validation of interviewer-and self-administered physical activity checklists for fifth grade students. Medicine and science in sports and exercise, 28(7), 840851. https://doi.org/10.1097/00005768-199607000-00011

Seabra. A. et al (2012). Gender, weight status and socioeconomic differences in psychosocial correlates of physical activity in schoolchildren. Journal of Science and Medicine in Sport, 16(4): 320-326. https://doi.org/10.1016/j.jsams.2012.07.008.

Shakib, S. et al (2011). Athletics as a Source for Social Status among Youth: Examining Variation by Gender, Race/Ethnicity, and Socioeconomic Status. Sociology of Sport Journal, 28(3): 303-328. https://doi.org/10.1123/ssj.28.3.303.

Silva, P. V. C \& Costa Junior, A. L. (2011). Efeitos da atividade física para a saúde de crianças e adolescentes. Psicologia Argumento, 29(64): 41-50. Recuperado em 26 de abril de 2021. https://periodicos.pucpr.br/index.php/psicologiaargumento/article/view/19915.

Silva, A. M. \& Damiani, I. R. (2005). As práticas corporais na contemporaneidade: pressupostos de um campo de pesquisa e intervenção social. In: Práticas Corporais: Gênese de um Movimento Investigativo em Educação Física. Florianópolis: Nauemblu Ciência \& Arte, 17-28.

Souza, J. (2003). (Não) Reconhecimento e subcidadania, ou o que é "ser gente"? Lua Nova: Revista de Cultura e Política, 59: 51-73. https://doi.org/10.1590/S010264452003000200003.

Souza, J. (2004). A gramática social da desigualdade brasileira. Revista Brasileira de Ciências Sociais, 19(54): 79-97. https://doi.org/10.1590/S0102-69092004000100005.

Souza, J. (2005a). (Sub)cidadania e naturalização da desigualdade: um estudo sobre o imaginário social na modernidade periférica. Política \& Trabalho, 22: 67-96. Recuperado em 26 de abril de 2021.

https://periodicos.ufpb.br/ojs/index.php/politicaetrabalho/article/view/6577.

Souza, J. (2005b). Raça ou classe? Sobre a desigualdade brasileira. Lua Nova, São Paulo, 65: 43-69. https://doi.org/10.1590/S0102-64452005000200003.

Souza, J. (2006). Para compreender a desigualdade brasileira. Teoria e Cultura, 1(2): 83-100. Recuperado em 26 de abril de 2021.

https://periodicos.ufjf.br/index.php/TeoriaeCultura/article/view/12120.

Souza, J. (2013a). Em defesa da Sociologia: o economicismo e a invisibilidade das classes sociais. Revista Brasileira de Sociologia, 1(1): 129-158. http://dx.doi.org/10.20336/rbs.27.

Souza, J. (2013b). As classes sociais e o mistério da desigualdade brasileira. In: Fundação Perseu Abramo E Fundação Friedrich Ebert (org.). Classes? Que classes? Ciclo de Debates sobre Classes Sociais. São Paulo: Editora Fundação Perseu Abramo, p. 53-64. 
D’Auria, B. B., Mezzaroba. C., \& Santos, S. M. dos. (2021, maio/ago.). Pertencimento à classe social e práticas corporais: revisando o tema na literatura e ensaiando relações possíveis

Souza, J. (2014). A cegueira do debate brasileiro sobre as classes sociais. Interesse Nacional, 7(27): 35-57. Recuperado em 26 de abril de 2021.

http://interessenacional.com.br/2014/10/01/a-cegueira-do-debate-brasileiro-sobre-asclasses-sociais/.

Stevens, M. et al (2017). A Social Identity Approach to Understanding and Promoting Physical Activity. Journal of Sports Medicine, 47(10): 1911-1918. https://doi.org/10.1007/s40279-017-0720-4.

Tammelin, T. S. et al (2003). Physical activity and social status in adolescence as predictors of physical inactivity in adulthood. Preventive Medicine, 37(4): 375-381. https://doi.org/10.1016/S0091-7435(03)00162-2.

Viana, M. S. (2014). Atividade Física na adolescência: Influência da motivação e dos fatores associados. 291f. Tese de doutorado- UDESC, Florianópolis.

Walters, S. M. D. et al (2008). Does Participation in Organized Sports Predict Future Physical Activity for Adolescents from Diverse Economic Backgrounds? Journal of Adolescent Health, 44(3): 268-274. https://doi.org/10.1016/j.jadohealth.2008.08.011.

Weir, L. A.; Etelson, D. \& Brand, D. A. (2006). Parents' perceptions of neighborhood safety and children's physical activity. Preventine Medicine, 43(3): 212-217. https://doi.org/10.1016/j.ypmed.2006.03.024.

Wijtzes, A. I. et al (2014). Social inequalities in young children's sports participation and outdoor play. International Journal of Behavioral Nutrition and Physical Activity, 11(1): 210. https://doi.org/10.1186/s12966-014-0155-3.

Zioni, F. \& Westphal, M. F. (2007). O enfoque dos determinantes sociais de saúde sob o ponto de vista da teoria social. Saúde e Sociedade, São Paulo, 16(3): 26-34. https://doi.org/10.1590/S0104-12902007000300004. 